\title{
Assessment of soil compaction properties based on surface wave techniques
}

\author{
Nur Jihan Syamimi Jafri ${ }^{1, *}$, Mohd Asri Ab Rahim ${ }^{1}$, Mohd Zulham Affandi Mohd Zahid ${ }^{2}$, \\ Nor Faizah Bawadi ${ }^{1}$, Muhammad Munsif Ahmad ${ }^{2}$, Ahmad Faizal Mansor ${ }^{2}$, and Wan Mohd \\ Sabki Wan Omar ${ }^{1}$ \\ ${ }^{1}$ School of Environmental Engineering, Universiti Malaysia Perlis, Kompleks Pusat Pengajian Jejawi \\ 3, 02600 Arau, Perlis, Malaysia \\ ${ }^{2}$ Department of Civil Engineering Technology, Faculty of Engineering Technology, Universiti \\ Malaysia Perlis, 02100 Padang Besar, Perlis, Malaysia
}

\begin{abstract}
Soil compaction plays an important role in every construction activities to reduce risks of any damage. Traditionally, methods of assessing compaction include field tests and invasive penetration tests for compacted areas have great limitations, which caused time-consuming in evaluating large areas. Thus, this study proposed the possibility of using non-invasive surface wave method like Multi-channel Analysis of Surface Wave (MASW) as a useful tool for assessing soil compaction. The aim of this study was to determine the shear wave velocity profiles and field density of compacted soils under varying compaction efforts by using MASW method. Pre and post compaction of MASW survey were conducted at Pauh Campus, UniMAP after applying rolling compaction with variation of passes (2,6 and 10). Each seismic data was recorded by GEODE seismograph. Sand replacement test was conducted for each survey line to obtain the field density data. All seismic data were processed using SeisImager/SW software. The results show the shear wave velocity profiles increase with the number of passes from 0 to 6 passes, but decrease after 10 passes. This method could attract the interest of geotechnical community, as it can be an alternative tool to the standard test for assessing of soil compaction in the field operation.
\end{abstract}

\section{Introduction}

Soil compaction is an important process in every construction activities in order to increase the bearing capacity of soil. It involved the densification of the ground by applying the mechanical energy such as static compaction, sheepsfoot, vibratory roller and plates, rammers, heavy tamping, vibroflotation and rolling dynamic compaction [1]. Conventionally, the assessment of soil compaction is conducted by soil sampling and laboratory or field testing such as Standard Penetration Test (SPT), Cone Penetration Test (CPT), Dynamic Cone Penetrometer (DCP), in-situ density tests, etc. These techniques are widely accepted within geotechnical projects. However, these techniques are caused time-

\footnotetext{
*Corresponding author: nurjihansyamimi@gmail.com
} 
consuming to cover large areas. The assessment process must be fast to produce results in the field for immediate assessment and directly evaluate the improvement of properties as an alternative to empirical correlations [2].

Recent years, the surface wave methods have been widely used in many geotechnical engineering projects in terms of cost and time effective compared to the conventional techniques. These applications include assessment of liquefaction potential [3], geotechnical verification of compaction $[2,4,6]$, and site characterization [5]. These nondestructive methods have been proved to be efficient compared to the conventional invasive mechanical techniques where the shear wave velocity $\left(V_{S}\right)$ is theoretically related to the shear modulus, $\mathrm{G}_{\max }$ as shown in the Equation 1 below:

$$
\mathrm{G}_{\max }=\rho \cdot \mathrm{V}_{\mathrm{S}}^{2}
$$

where, $\mathrm{G}_{\max }$ is the shear modulus (pa), $\mathrm{V}_{\mathrm{S}}$ is the shear wave velocity $(\mathrm{m} / \mathrm{s})$ and $\rho$ is the density $\left(\mathrm{kg} / \mathrm{m}^{3}\right)$.

Surface wave methods have utilised Rayleigh wave for near surface applications, where it travels along the free surface of the earth with elliptical retrograde particle motion. The use of surface waves for determining the dynamic properties of the subsurface are based on their dispersive characteristics, where the velocity propagation of Rayleigh wave is depend on the frequency. Thus, the higher frequency will penetrate the shallow layer while the low frequency will influenced the deeper material.

The first surface wave method was introduced [7], called as Spectral Analysis of Surface Waves (SASW) that used the spectral analysis of ground roll generated by an impulsive source and recorded by two receivers to generate the near-surface of $V_{S}$ profile. This method is widely used in evaluation of pavement systems [8], evaluation of compacted ground $[9,10]$ and site characterization [11]. However, a new method called Multichannel Analysis of Surface Waves (MASW) has introduced, to develop an efficient and accurate method to estimate near-surface $\mathrm{V}_{\mathrm{S}}$ from ground roll. MASW technique has developed to overcome the weaknesses of the SASW, which used the dispersion characteristics of Rayleigh waves to determine the variation of the $V_{S}$ in layered systems with depth [12]. MASW technique is an ideal tool to speed up the control process in the evaluation of ground modifications without the requirement to include geogrid reinforcement [2]. MASW technique is a cost-effective tool for obtaining reliable shear wave velocity profiles in estimation the engineering properties of soil [3].

Tokeshi et al. [5] has investigated the use of the non-invasive Multichannel Analysis of Surface Wave (MASW) and Multichannel Simulation with One Receiver (MSOR) techniques to provide an evaluation of compacted ground and a general geotechnical site characterization. The results from both techniques were verified against CPT and SPT data. The correlation observed between the experimental Rayleigh dispersion and the $\mathrm{V}_{\mathrm{S}}$ ground model estimated from Rayleigh dispersion inversion has confirmed these techniques are useful for evaluating the Vs ground profile. In agricultural, Donohue et al., [13] also explored the possibility of MASW for assessment of agricultural compaction in a field environment. The results show the significance difference in shear wave velocity between heavily compacted headland and uncompacted soil. The results from this approach has compared with those obtained from measurement of bulk density and penetrometer resistance. However, there is limitation of the surface wave approach for detection compaction, which is the resolution of the technique at very shallow depths.

This paper presented the evaluation of soil compaction after applying the roller compaction using Multichannel Analysis of Surface Wave (MASW) method. The aim of this paper is to determine the shear wave velocity profiles and field density of compacted soils under varying compaction efforts by using MASW method. 


\section{Methods}

\subsection{Site location}

The test site is shown in Fig. 1(a), which is located near to Litar Pauh Putra Campus, UniMAP. The site has 5 meters depth of soil and was reclaimed using fill material of well graded sandy gravel. The testing was carried out in two stages: before compaction and after compaction. During the first stage, the MASW survey and sand replacement were conducted on the single line survey. The second stage, a 16-tonne roller compactor was used with 2, 6 and 10 passes, continued with the MASW survey and sand replacement test. Fig. 1(b) showed a layout plan of the survey area.

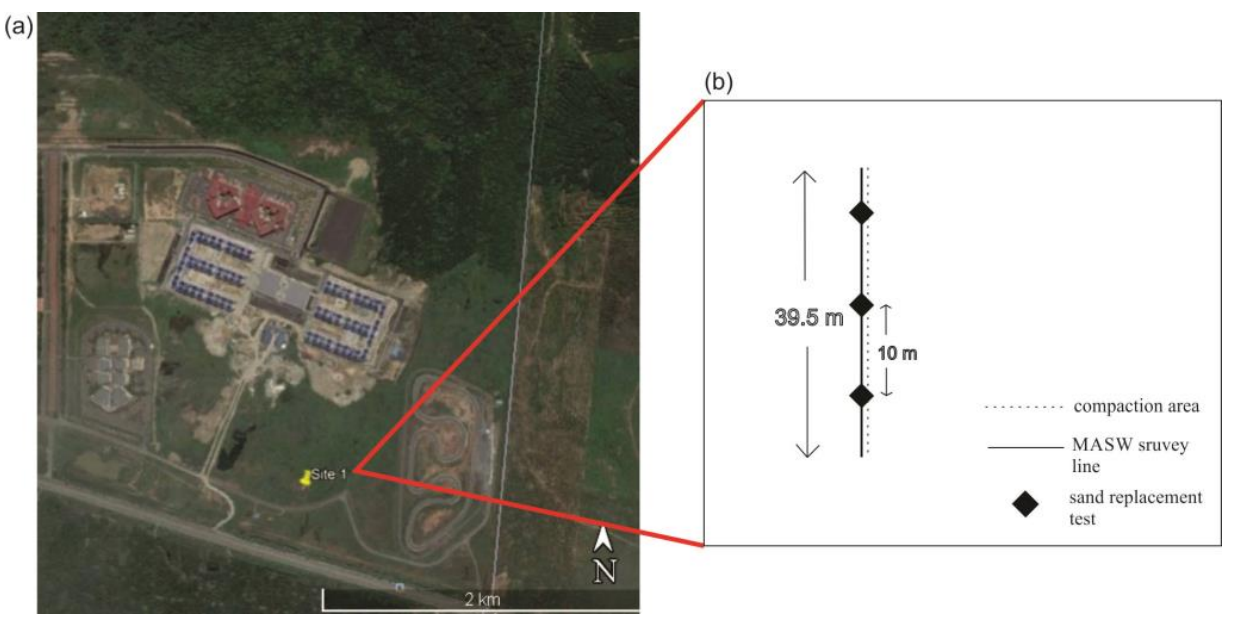

Fig. 1. (a) The site location is shown in Google Earth image and (b) Layout plan of the survey area.

\subsection{In-situ density test}

Sand replacement method was performed by following the procedure of BS 1377:Part 9:1990 [14] to determine in-situ density of compacted soils. The calibration was conducted before doing the testing to determine the mass of sand in the pouring cylinder. The sampling was performed at three locations along the MASW survey line, as presented in Fig. 1(b) to obtain the mean mass of dry densities of the soil.

Along the survey line, the metal tray was laid and a round hole was excavated approximately $100 \mathrm{~mm}$ in diameter and maximum of $150 \mathrm{~mm}$ deep into the ground. All excavated soil from the hole was collected to determine the mass of sand. Then, the pouring cylinder with sand filled was placed on the excavated hole and allowed sand to fill the hole until no movement of the sand. The cylinder was removed. After the mass of poured sand, bulk density of sand and soil, mass of sand filled in the hole and moisture content of the soil was calculated, the dry density of the soil was determined.

\subsection{MASW data acquisition and processing}

For this testing, $7 \mathrm{~kg}$ sledgehammer was used as the seismic source by hitting the striker plate. The seismic source was positioned at $5 \mathrm{~m}$ from the first geophone. 24 units of $4.5 \mathrm{~Hz}$ 
vertical geophones were deployed vertically and firmly with equal interval on the soil. The spacing between geophones was kept at $1.5 \mathrm{~m}$, which resulted in a total receiver array length of $34.5 \mathrm{~m}$ as shown in Fig. 2. The geophones were connected to the spread cable and recorded using a 24-channel Geode seismograph.

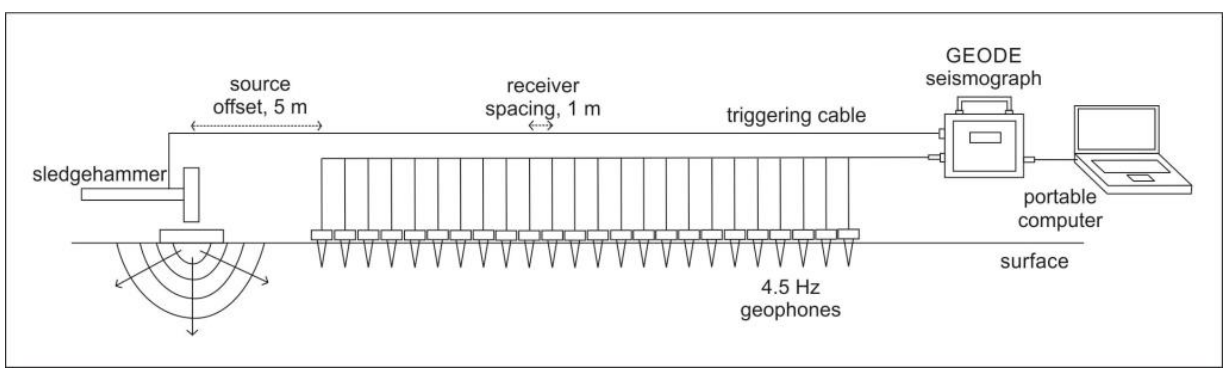

Fig. 2. The field configuration of MASW survey.

(a)

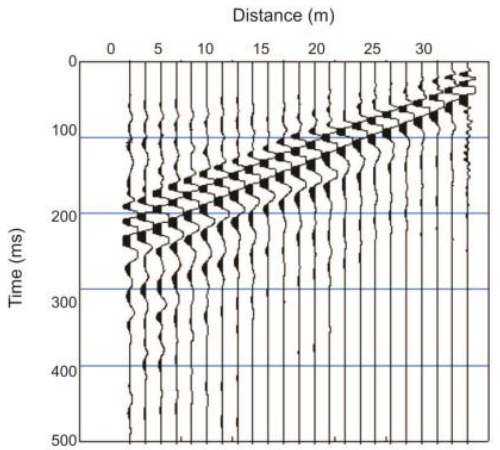

(c)

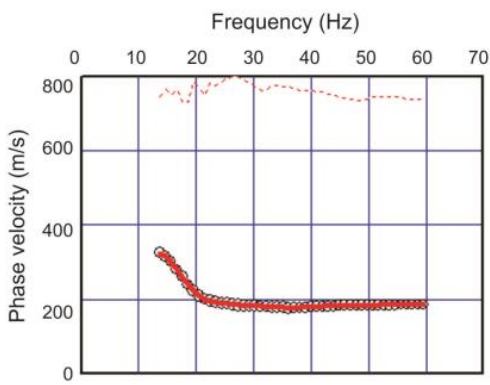

(b)

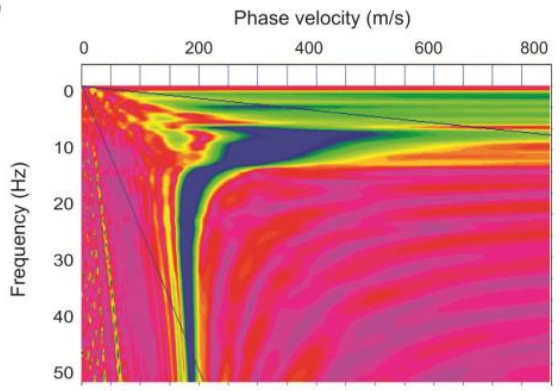

(d)

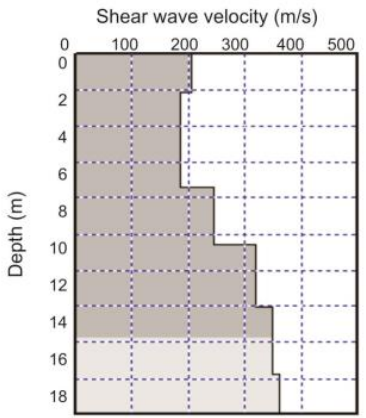

Fig. 3. The procedure of MASW data processing using SeisImager software, a) detection of surface waves, b) image of dispersion curve, c) inversion of dispersion curve, d) 1D shear wave velocity profile.

In order to reduce background noise and prevent interference with resolution and accuracy of the data, the data were acquired by hitting the striker plate during periods of little nearby traffic and/or wind. For data acquisition, the recording time and sampling intervals were set at 1 second and 0.5 milliseconds with three times stacking.

The seismic raw data were processed and analysed using SeisImager/SW software. The procedure of MASW consists of three steps: (1) active data acquisition, (2) developing the 
dispersion curves and (3) inversion of dispersion data to obtain the shear wave velocity profiles. Fig. 3(a) shows the raw wiggle plot obtained from the field test. The recorded seismic waves were analysed to generate phase velocity images in frequency domain as shown in Fig. 3(b). Then, the dispersion curves were constructed from the phase velocity images using the signal-to-noise ratio (Fig. 3c). The phase velocity image was chosen in the frequency range between 5 to $65 \mathrm{~Hz}$. The inversion of dispersion curve was applied using a non-linear square technique to generate the one-dimensional shear wave velocity profile, as illustrated in Fig. 3(d) [12].

\section{Results and discussions}

\subsection{Dry density of compacted soils}

Table 1 shows the results of dry density from MASW survey and sand replacement test. In general, dry density of the ground and the number of passes will increases with depth of soil. However, there were inconsistent results of dry density at the surface of the ground from sand replacement method and MASW as the number of passes increase. This condition explained that the area was reclaimed using fill material of well graded sandy gravel. Thus, it can be due to the reclamation process, the soil particles are in stage to firm.

Table 1. Results of dry density from MASW and sand replacement tests

\begin{tabular}{|c|c|c|c|c|c|}
\hline $\begin{array}{l}\text { No. of } \\
\text { passes }\end{array}$ & $\begin{array}{c}\text { Shear wave } \\
\text { velocity } \\
\text { (m/s) below } \\
1 \mathrm{~m}\end{array}$ & $\begin{array}{c}\text { Dry density } \\
\left(\mathrm{Mg} / \mathrm{m}^{3}\right) \text { from } \\
\text { sand replacement }\end{array}$ & $\begin{array}{c}\text { Moisture } \\
\text { content } \\
(\%)\end{array}$ & $\begin{array}{c}\text { Dry density } \\
\left(\mathbf{M g}^{3} \mathbf{m}^{3}\right) \\
\text { from MASW }\end{array}$ & $\begin{array}{l}\text { Percentage } \\
\text { difference of } \\
\text { dry density } \\
(\%)\end{array}$ \\
\hline 0 & $192-205$ & 1.75 & 0.76 & 1.79 & 2.23 \\
\hline 2 & $170-181$ & 1.79 & 0.72 & 1.78 & 0.56 \\
\hline 6 & $178-190$ & 1.73 & 2.05 & 1.79 & 3.35 \\
\hline 10 & $175-189$ & 1.77 & 1.34 & 1.79 & 1.12 \\
\hline
\end{tabular}

The density from MASW test was calculated using the Equation 2 from Ludwig et al. [15] and the results of soil density with depth from MASW tests is illustrated in Fig. 4.

$$
\rho=1.2475+0.399 \mathrm{~V}_{\mathrm{p}}-0.026 \mathrm{~V}_{\mathrm{p}}^{2}
$$

\subsection{Shear wave velocity profile}

The results of the shear wave velocity profile for before and after compaction with 2,6 , and 10 passes has shown in Fig. 4. Generally, the shear wave velocity will increase with depth as the number of passes increases. The ranges of shear wave velocity before compaction (18 m depth from surface) is between $192 \mathrm{~m} / \mathrm{s}$ to $537 \mathrm{~m} / \mathrm{s}$. From ground surface to $3 \mathrm{~m}$ depth, the shear wave velocity has decreased after compaction started. This resulted affected due to the process of soil reclamation after applying roller compactor.

Meanwhile, the shear wave velocity for 2 and 6 passes has increased about 7 to 100 $\mathrm{m} / \mathrm{s}$ at 1 to $18 \mathrm{~m}$ depth. This indicates that the soil density increases as the number of passes increases. However, after 10 passes of compaction, shear wave velocity has decreased at 4.5 to $18 \mathrm{~m}$ depth. The results in $\mathrm{V}_{\mathrm{S}}$ inconsistencies in depth cause due to the low resolution during the process of dispersion curve in picking for low frequencies [3]. 

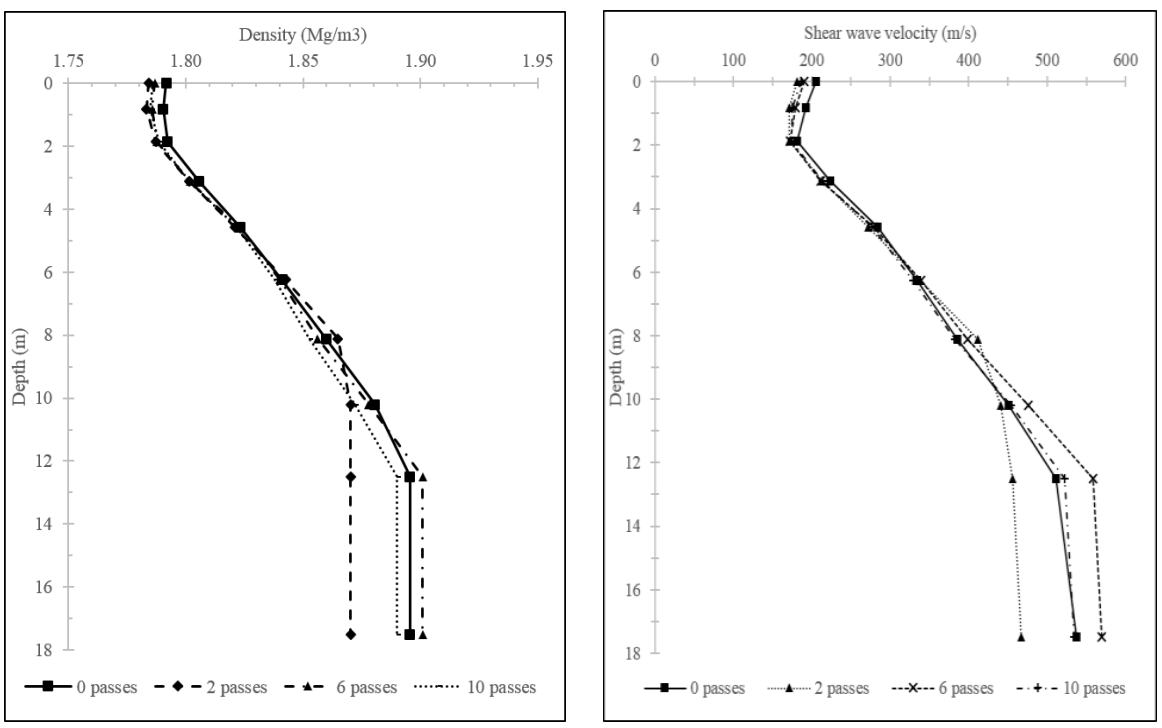

Fig. 4. Soil density and shear wave velocity profile of MASW with different number of passes.

\section{Conclusions}

The shear wave velocity profiles of before compaction and after compaction were determined using Multi-channel Analysis of Surface Wave (MASW) technique. This research has achieved the objective where the percentage differences of dry density from field density test and MASW survey is less than 10\% of standard acceptance, thus achieved a requirement of geotechnical design. The MASW method can be an alternative tool to the standard test for assessing of soil compaction in the field. In addition, MASW method has the advantage of being fast, practical and non-destructive tool for engineers in measuring dry density and shear wave velocity compared to the conventional methods. The procedures of this method need to be explored in depth since it is suitable and more time effective in evaluating the large areas.

The author would like to acknowledge Ministry of Higher Education (MOHE), Malaysia for the sponsor and financial support received from Fundamental Research Grant Scheme (FRGS: 900300546).

\section{References}

1. M. R. Hausmann, Engineering Principles of Ground Modification. New York, McGraw-Hill (1990)

2. A. Bouazza and D. L. Avalle, Australian Geomech, 41, 101-108 (2006)

3. C. P. Lin, C. C. Chang, T. S. Chang, Soil Dyn Earthq Eng, 24, 689-698 (2004)

4. R. J. Whiteley, P. Caffi, Near Surface Geophysics 12, 405-414 (2014)

5. K. Tokeshi, P. Harutoonian, C. J. Leo, S. Liyanapathirana, Adv. Geosci., 35, 37-44 (2013) 
6. S. Donohue, and L. Michael, Near Surface Geophysics (2008)

7. S. Nazarian, K. H. Stokoe, Research Rep. 256-264 (1983)

8. S. Nazarian, K. H. Stokoe, W. R. Hudson, Transportation Research Record, 38-45 (1983)

9. D. S. Kim, M. K. Shin, H. C. Park, Soil Dyn Earthq Eng 21, 39-46 (2001)

10. A. Bitri, K. Samyn, S. Brûlé, E. H. Javelaud, Geotechnical Assessment and Geoenvironmental Eng., 11, 683-690 (2013)

11. T. L. Goh, A.R. Samsudin, A. G. Rafek, Application of spectral analysis od surface waves (SASW) method: rock mass characterization, Sains Malaysiana, 40, 425-430 (2011)

12. C. B. Park, R. D. Miller, J. Xia, Multichannel analysis of surface waves. Geophy., 64, 800-808 (1999)

13. S. Donohue, F. Dermot, A. L. Donohue, Detection of soil compaction using surface waves, Soil and Tillage Research, 128, 54-60 (2013)

14. Methods for test for soils for civil engineering purposes, In-situ tests, BS 1377-9:1990

15. W. J. Ludwig, J. E. Nafe, C. L. Drake, The Sea, 4, 53-84 (1970) 